\title{
A cobertura vacinal do HPV no município de Cajazeiras, estado da Paraíba (nordeste do Brasil)
}

\author{
Mariana Alexandre Gadelha de Lima ${ }^{1}$ (D) Alessandra Emilly Pinto de Assis ${ }^{1}$ (D), \\ Irlla Jorrana Bezerra Cavalcante ${ }^{1}$ (D), Moacir Andrade Ribeiro Filho ${ }^{2}$ (1) \& \\ Symara Abrantes Albuquerque de Oliveira Cabral $^{1}$ (D)
}

(1) Universidade Federal de Campina Grande, Centro de Formação de Professores, Unidade Acadêmica de Enfermagem, Rua Sérgio Moreira de Figueiredo, Casas Populares 58900-000, Cajazeiras, Paraíba, Brasil. E-mail: marianaalexandre15@gmail.com, symara.abrantes@professor.uf cg.edu.br

(2) Hospital Regional de Cajazeiras, Rua Tabelião Antonio Holanda, Cristo Rei 58900-000, Cajazeiras, Paraíba, Brasil. E-mail: moacirarf@outlook.com

Lima M.A.G., Assis A.E.P., Cavalcante I.J.B., Ribeiro Filho M.A. \& Cabral S.A.A.O. (2021) A cobertura vacinal do HPV no município de Cajazeiras, estado da Paraíba (nordeste do Brasil). Pesquisa e Ensino em Ciências Exatas e da Natureza, 5(edição especial 1): e1659.

http://dx.doi.org/10.29215/pecen.v5i1.1659

Responsabilidade editorial: Carla Heloísa Alencar de Figueiredo. Recebido: 15 dezembro 2020. Aceito: 18 fevereiro 2021. Publicado: 26 fevereiro 2021.

Resumo: O Câncer de Colo Uterino é nocivo à saúde da mulher, sendo o quarto câncer mais comum nessa população. Esse tipo de câncer, ocasionado pelo Papilomavírus Humano, é altamente contagioso. A transmissão pode ocorrer numa única exposição por contato direto com a mucosa infectada ou através da pele. $\mathrm{O}$ vírus pode estar presente no corpo por anos, sem manifestar a sintomatologia. Como prevenção, menciona-se a imunização. Adolescentes tem se tornado sexualmente ativos de forma prematura, o que influencia na prevalência do Papilomavírus nesse segmento social. Em 2013, o Ministério da Saúde implementou a vacina contra o Papilomavírus no calendário vacinal de adolescentes. Este trabalho objetiva conhecer essa cobertura vacinal no município de Cajazeiras, estado da Paraíba, nordeste do Brasil. Trata-se de um estudo ecológico, exploratório, com dados secundários. Os dados sobre a cobertura vacinal do público feminino em Cajazeiras nos anos de 2014, 2015 e 2017 foram encontrados no Sistema de Informações do Programa Nacional de Imunizações. Em 2014, a primeira dose da vacina foi disponibilizada com 1.377 meninas vacinadas. Na segunda dose, o número diminui com 904 meninas vacinadas. Em 2015, o quantitativo decresceu: 868 receberam a primeira dose e 517 receberam a segunda dose. Em 2017, apenas 317 meninas foram vacinadas.

Palavras chave: Infecções por Papillomavirus, neoplasias do colo do útero, vacina quadrivalente recombinante contra HPV, saúde do adolescente.

\section{Vaccination coverage of HPV in the municipality of Cajazeiras, state of Paraíba (northeastern Brazil)}

Abstract: Cervical cancer is harmful to women's health, being the fourth most common cancer in this population. This type of cancer, caused by the Human Papillomavirus, is highly contagious. Transmission can occur in a single exposure by direct contact with the infected mucosa or through the skin. The virus can be present in the body for years, without manifesting the symptoms. As a prevention, immunization is mentioned. Adolescents have become sexually active prematurely, which influences the prevalence of Papillomavirus in this social segment. In 2013, the Ministry of Health implemented the vaccine against Papillomavirus in the adolescent vaccination calendar. This work aims to know this vaccination coverage in the municipality of Cajazeiras, Paraíba. This is an ecological, exploratory study with secondary data. Data on vaccination coverage for the female public in Cajazeiras in 2014, 2015 and 2017 were found in the Information System of the National Immunization Program. In 2014, the first dose of the vaccine was made available with 1.377 girls vaccinated. In the second 
dose, the number decreases with 904 girls vaccinated. In 2015, the number decreased: 868 received first dose and 517 received second dose. In 2017, only 317 girls were vaccinated.

Key words: Papillomavirus infections, uterine cervical neoplasms, recombinant human papillomavirus (HPV) quadrivalent vaccine, adolescent health.

O Câncer de Colo de Útero (CCU) representa risco à saúde da mulher. De acordo com o Instituto Nacional de Câncer (INCA), a cada ano, mundialmente, ocorrem 570 mil novos casos e 311 mil óbitos em decorrência dessa doença, que ocupa a quarta causa de câncer mais comum entre as mulheres. No Brasil, em 2019, 6.596 mulheres foram a óbito; em 2020, são previstos novos 16.710 mil casos (INCA 2021).

Papilomavírus Humano, em inglês Human Papiloma Virus (HPV), é o vírus causador do CCU. Com mais de 150 diferentes tipos de HPV, 40 possuem capacidade infecciosa no trato genital, sendo que 12 representam um alto risco devido a sua capacidade oncológica, além de outros que podem ocasionar verrugas genitais. Entre os tipos de HPV com potencial oncogênico, os tipos 16 e 18 são os mais comuns, estando presentes em 70\% dos casos (BRASIL 2014a).

Com alto nível de contágio, a transmissão pode acontecer em uma única exposição por contato direto com a mucosa infectada ou a pele. $\mathrm{O}$ vírus do HPV pode estar presente no corpo por anos, sem manifestar a sintomatologia. Quando a mulher é exposta e contaminada com alguns tipos de HPV, seu corpo não possui capacidade imunológica para exterminar a infecção, ocorrendo, assim, o desenvolvimento de células anormais, que irão revestir o colo uterino. Quando essa anormalidade não é descoberta e tratada a tempo, acontece a evolução de um précâncer para o câncer. Trata-se de um processo que leva anos, podendo ocasionar sintomas como sangramento vaginal, dor e corrimento (BRASIL 2014a).

Como medida profilática, menciona-se a imunização como alternativa eficaz ao combate do HPV. Segundo Zardo et al. (2014), países que adotaram a vacina contra essa doença em seu calendário vacinal diminuíram em até $90 \%$ o contágio ocasionado por esse vírus. Com base nas boas experiências que o sistema de saúde do Brasil possui sobre a vacinação, deve-se ressaltar a possibilidade de promover de forma eficiente a imunização contra os tipos de HPV para o público-alvo.

Tendo em vista a alta morbimortalidade do câncer de colo uterino no Brasil, o Ministério da Saúde promoveu estudos que pudessem analisar cenários distintos, com a finalidade de introduzir a vacina do HPV no Sistema Único de Saúde (SUS). A partir do resultado positivo e da manifestação favorável do Comitê Técnico Assessor em Imunizações (CTAI), em 2012, um grupo técnico foi formado para traçar um plano de vacinação baseado na realidade nacional (BRASIL 2014b).

A Secretaria de Ciência e Tecnologia (SCTIE) do Ministério da Saúde também cumpriu seu papel nessa caminhada, ao subsidiar diálogos entre laboratórios dos setores público e privado, objetivando a garantia da produção desse agente imunizante dentro do país e o seu fornecimento ao Programa Nacional de Imunização. Esse apoio garante a sustentabilidade de ações que assegurem o abastecimento de mais de 30 mil salas de vacinas existentes em todo o território nacional. Em julho de 2013, a vacina do HPV foi incluída no Calendário Nacional de Vacinação do Adolescente como uma medida de saúde pública que visava o reforço de medidas profiláticas ao câncer de colo do útero (BRASIL 2014b).

A forma precoce que adolescentes se tornam sexualmente ativos se associa à frequência da presença do HPV nesse público. A introdução prematura de meninas na vida sexual, muitas vezes, reflete na existência de múltiplos parceiros, com relações que podem ocorrer sem o uso de preservativos. Mesmo quando há o uso de preservativo, tendo em vista as formas de transmissão do HPV, a contaminação ainda é um risco. Todos esses fatos possuem viés socioeconômico e cultural (Almeida et al. 2014).

Nesse sentido, com base na importância que a vacina do HPV possui frente ao combate contra o câncer uterino e de outras infecções associadas ao vírus, torna-se relevante conhecer e 
analisar a sua cobertura vacinal diante de adolescentes do sexo feminino. Neste trabalho, temos como objetivo conhecer a cobertura vacinal do HPV no município de Cajazeiras - Paraíba.

Trata-se de um estudo ecológico, exploratório, com dados secundários. As informações referentes à cobertura vacinal do público feminino, em Cajazeiras, nos anos de 2014, 2015 e 2017, foram encontradas no Sistema de Informações do Programa Nacional de Imunizações (SIPNI) do Departamento de Informática do Sistema Único de Saúde do Brasil (DATASUS). Menciona-se a limitação acerca da falta de informações sobre a cobertura vacinal de outros anos. Assim como no estudo de Souza et al. (2020), a ausência desses dados vacinais foi um limitante para o conhecimento da situação desses imunizantes nos demais períodos sucessores.

Em 2014, primeiro ano da campanha de vacinação contra o HPV, a primeira dose (D1) da vacina foi disponibilizada e 1.377 meninas foram vacinadas no município de Cajazeiras. Já na segunda dose (D2), o número caiu para 904 meninas. No ano seguinte, a cidade viu esse quantitativo continuar a decrescer: 868 meninas receberam a D1 e apenas 517 receberam a D2. Em 2017, mais uma vez o número apresentou uma queda com apenas 317 meninas vacinadas.

A justificativa para a alta adesão à vacina contra o HPV em 2014 foi o espaço utilizado para dar início à campanha, sendo a escola o local utilizado para a aplicação das doses. Tem-se, portanto, que o ambiente escolar é um cenário oportuno para se trabalhar campanhas que visam o bem-estar de crianças e adolescentes.

Nota-se que nos anos seguintes houve um decréscimo no número de meninas que foram imunizadas contra o HPV. Isso ocorreu devido à mudança de ambiente: a escola deixou de ser o local estratégico para as aplicações das doses, que foram transferidas para as salas de vacinas de Unidades Básicas de Saúde (UBSs).

Nesse sentido, é importante salientar que a proteção eficaz se dá por meio do preenchimento do esquema vacinal. Ao receber a primeira dose, ocorre a produção de anticorpos, mas ainda assim não é um quantitativo suficiente para desenvolver uma resposta imunológica satisfatória para a infecção por HPV. Logo, torna-se imprescindível tomar a outra dose da vacina (Pereira \& Souza 2017).

Osis et al (2014) dizem que em um município do Estado de São Paulo, onde a primeira dose foi feita em sala de aula, houve uma boa aceitação. Isso porque os pais e responsáveis receberam informações pertinentes sobre a importância da vacina contra o HPV. Com esse compartilhamento de conhecimentos, $97 \%$ das adolescentes completaram o esquema de doses.

Entretanto, o diálogo a ser estabelecido com pais e responsáveis deve estar além das informações relacionadas a vacina em si. Questões religiosas permeiam as discussões acerca da vacinação contra o HPV. Pais de adolescentes evangélicas ou católicas encaram essa prevenção como uma ordem do Estado, de caráter questionável, que causa influência no comportamento de meninas. Na percepção deles, a vacina seria um incentivo à iniciação sexual precoce, logo, a melhor forma de prevenir infecções causadas pelo HPV é a fidelidade ao casamento (Quevedo et al. 2016).

Além de questões religiosas, a vacinação contra o HPV enfrenta outros impasses diante da aceitabilidade do público. De acordo com Carvalho et al. (2019), existem fatores individuais, sociais e programáticos sobre a adesão à imunização. Dentre os aspectos individuais, mencionase o conhecimento sobre o HPV e infecções associadas e informações sobre a vacina referentes à segurança e eficácia. Já nas dimensões programáticas, cita-se a oferta do imunizante no ambiente escolar e o papel de professores e profissionais da saúde sobre a recomendação de se vacinar. A dimensão social envolve o conhecimento que a família tem sobre os riscos do HPV e o apoio desta sobre a prevenção imunológica.

Sensibilizar adolescentes sobre a importância da prevenção imunológica contra o HPV é um passo importante para uma cobertura vacinal e consequente avanço na saúde pública. Em seu estudo, Juberg et al. (2015) falam sobre esse desconhecimento de adolescentes sobre a campanha contra o HPV e a vacinação. Em sua pesquisa, ficou evidenciado que mais de $70 \%$ da amostra desconhecia a relação entre o vírus, o CCU, dentre outras doenças oncológicas. Isso refletia que as campanhas sobre a doença e a prevenção não estavam tendo uma resposta eficaz. Os autores reforçam a relevância de que estudos confirmem esses achados e que estes sirvam de 
subsídios para a elaboração de campanhas que possam abranger efetivamente esse conhecimento do público-alvo.

Quevedo et al. (2016) citam a comunicação como parte desse processo de adesão à vacinação, sendo que o desempenho exitoso depende de agentes que aproximam essa inovação do cotidiano. Baseado no sucesso que a campanha teve quando foi iniciada em sala de aula, mencionam-se professores e demais gestores escolares como figuras que podem cumprir esse papel de sensibilizar pais e alunos a aderir à vacina. A escola é um espaço oportuno para se trabalhar questões de saúde que envolvem o bem-estar de crianças e adolescentes.

Outra figura que tem um papel crucial na sensibilização da sociedade para participação de debates em saúde é o profissional dessa área. Visto que a UBS é o ambiente onde ocorre a vacinação e tendo em consideração o enfermeiro como gerente desse espaço, torna-se viável que esse estabeleça diálogo com escolas da área. Por meio desta parceria, profissionais da saúde e da educação podem discutir junto à comunidade a importância da vacinação contra o HPV. A discussão deve permear os anseios coletivos e individuais, com base nas crenças e culturas.

O CCU possui um impacto significativo na saúde pública. A vacinação contra o HPV se mostra como uma alternativa de prevenção eficaz, juntamente com a educação em saúde, que sensibiliza o público-alvo a adotar medidas profiláticas. Entretanto, a vacina permeia questões socioculturais, que ditam sobre a adesão do público-alvo sobre a proposta. Nesse sentido, torna-se fundamental o conhecimento do profissional da atenção primária sobre esses impasses, na finalidade de discuti-los de forma ampla, respeitando as individualidades, de modo que essas se sensibilizem à imunização. A escola e seus agentes também são mediadores desse processo, onde podem proporcionar discussões e orientações frente a essa questão. Reforça-se ainda a importância de subsidiar melhor as bases de dados referentes à vacinação contra o HPV, uma vez que esses meios são fonte de informação e direcionamento de estratégias para uma cobertura cada vez maior.

\section{Referências}

Almeida F.L., Beiral J.S., Ribeiro K.R., Shimoda E. \& Souza C.H.M. (2014) A vacina contra o vírus hpv para meninas: um incentivo à vida sexual precoce? Revista Científica Interdisciplinar, 1(1): 49-71. https://doi.org/10.17115/2358-8411/v1n1a3

BRASIL (2014a) Ministério da Saúde, Secretaria de Vigilância em Saúde Departamento de Vigilância de Doenças Transmissíveis. Coordenação Geral do Programa Nacional de Imunizações. Guia Prático sobre o HPV. Brasília: Ministério da Saúde. 42 p.

BRASIL (2014b) Ministério da Saúde, Secretaria de Vigilância em Saúde Departamento de Vigilância de Doenças Transmissíveis. Coordenação Geral do Programa Nacional de Imunizações. Informe técnico sobre a vacina Papilomavírus Humano (HPV) na Atenção Básica. Brasília: Ministério da Saúde. 36 p.

Carvalho A.M.C., Andrade E.M.L.R., Nogueira L.T. \& Araújo T.M.E. (2019) Adesão à vacina HPV entre os adolescentes: revisão integrativa. Texto e Contexto Enfermagem, 28: 1-15. http://dx.doi.org/10.1590/1980-265x-tce-2018-0257

INCA (2021) Instituto Nacional de Câncer: Controle do Câncer do Colo do Útero. Disponível em: https://www.inca.gov.br/controle-do-cancer-do-colo-do-utero/conceito-e-magnitude\#: :tex $\mathrm{t}=$ Com $\%$ 20aproximadamente\%20570\%20mil\%20casos,por\%20c\%C3\%A2ncer\%20em\%20mul heres1 (Acessado em 07/02/2021).

Jurberg C., Machado G.O.C., Biancovilli P., Lima F.T. \& Verjovsky M. (2015) Conhecimento sobre o HPV entre adolescentes durante a campanha de vacinação. Adolescência \& Saúde, 12(4): 29-36.

Osis M.J.D., Duarte G.A. \& Sousa M.H. (2014) Conhecimento e atitude de usuários do SUS sobre o HPV e as vacinas disponíveis no Brasil. Revista de Saúde Pública, 48(1): 123-133. https://doi.org/10.1590/S0034-8910.2014048005026

Pereira F.B. \& Souza É.P. (2017) Cobertura Vacinal do HPV para Adolescentes: Desafios e Possibilidades. Id on Line Revista Multidisciplinar e de Psicologia, 11(38): 530-540. 
Quevedo J.P., Inácio M., Wieczorkievicz A.M. \& Invernizzi N. (2016) A política de vacinação contra o HPV no Brasil: a comunicação pública oficial e midiática face à emergência de controvérsias. Revista Tecnologia e Sociedade, 12(24): 1-26.

Souza W.M., Silva A.D., Santos A.D., Soares S., Morone A.R. \& Santos F. (2020) Análise da imunização contra o HPV no Brasil: um estudo ecológico exploratório de 2016 a 2018 . Revista Eletrônica de Ciência, Tecnologia e Inovação em Saúde, 1: 1-9. http://dx.doi.org/10.9789/26754932.rectis.v1.9727

Zardo G.P., Farah F.P., Mendes F.G., Franco C.A.G.S., Molina G.V.M., Melo G.N. \& Kusma S.Z. (2014) Vacina como agente de imunização contra o HPV. Ciência \& Saúde Coletiva, 19(9): 3799-3808. https://doi.org/10.1590/1413-81232014199.01532013 